\title{
Primer ön çapraz bağ tamiri
}

\section{Primary anterior cruciate ligament repair}

\author{
Mahmut Enes Kayaalp ${ }^{1}$ Özgür Korkmaz², Lokman Kehribar ${ }^{3}$, Mahir Mahiroğulları ${ }^{4}$ \\ 'S.B. Taksim Eğitim ve Araştırma Hastanesi, Ortopedi ve Travmatoloji Kliniği, İstanbul \\ ${ }^{2}$ Bahçeşehir Üniversitesi, Ortopedi ve Travmatoloji Kliniği, Pendik Medikal Park VM Hastanesi, İstanbul \\ ${ }^{3}$ Gazi Devlet Hastanesi, Ortopedi ve Travmatoloji Kliniği, Samsun \\ ${ }^{4}$ Özel Muayenehane ve Vehbi Koç Vakfı Sağlık Kuruluşları Medamerikan Tıp Merkezi, İstanbul
}

Ön çapraz bağ hasarının tedavisinde primer tamir seçeneği, yeni geliştirilen teknikler ve ekipmanla günümüzde tekrar önem kazanma aşamasındadır. Bu derleme ile, bu durumun arkasındaki güncel bilimsel kanıt ve gerekçelerin irdelenmesi planlanmıştır. Ön çapraz bağın iyileşmesindeki biyolojik ve mekanik engellerin bertaraf edilebileceğinin görülmesi ile farklı tamir seçenekleri ortaya konulmuştur. Dinamik intraligamenter stabilizasyon (DiS) sistemi, bu sistemler arasında en yaygın kullanım alanına sahip olanlardan biridir. Primer tamir tedavisinde yöntemin önüne geçen, sonuçlar üzerinde etkili faktörlerden biri de hasta seçimidir. Doğru hasta seçimi için, yırtık morfolojisinin yanında hasta fonksiyonel ve demografik özellikleri de etkilidir. Bu derlemede, farklı tamir çeşitleri ele alınmış ve Dis özelinde, literatürdeki klinik araştırmalar ve konu temelinde yapılmış temel bilim araştırmaları değerlendirilmiştir. Güncel bilimsel kanıtların zemininde, Dis sisteminin seçilmiş hasta gruplarında önemli bir yeri olduğu anlaşılmaktadır. Var olan kullanım alanının değişmesinde, gelecek dönemde yapılacak bağımsız, geniş serili, karşılaştırmalı ve randomize çalışmaların etkisi olacaktır.

Anahtar sözcükler: primer ÖÇB tamiri; ön çapraz bağ; Dis; dinamik intraligamenter stabilizasyon; hasta seçimi
Primary anterior cruciate ligament repair gains interest owing to modern techniques and new devices. This review aims to examine the current scientific level of proof behind the primary repair option. New techniques in primary repair of ACL have been introduced following the notion that the ruptured ligament is capable of healing. Dynamic intraligamentary stabilization (DIS) is one of the most commonly preferred methods among primary repair options. A more prominent influencer of clinical results other that the repair option is the selection criteria of patients. Patient selection criteria not only include the tear morphology, but also patients' functional status and demographical features. This review examined various repair techniques and, specifically DIS method, clinical researches on it, and repair specific basic science researches. In the light of the currently available scientific proof, DIS has a prominent space in a correctly selected patient group. Future independent, comparative and randomized studies with larger cohorts will effect its place as an option in addressing ACL injuries.

Key words: primary ACL repair; anterior cruciate ligament; DIS; dynamic intraligamentary stabilization; patient selection

\section{Ö}

n çapraz bağ (ÖÇB) hasarı tanısı yıllar içerisinde giderek artan sıklıkta kaydedilmektedir. ${ }^{[1]}$ Sadece Amerika'da yıllık 200.000 ÖÇB rekonstrüksiyonu yapıldığı bildirilmiştir. Günümüzde ön çapraz bağ hasarında altın standart tedavi ön çapraz bağ rekonstrüksiyonudur. ${ }^{[2]}$

Ön çapraz bağ hasarının cerrahi tedavisinde rekonstrüksiyon dışı yöntemlerin uygulanmasına yönelik 1950'li yıllardan beri ciddi çabalar olmuştur. ${ }^{[3,4]}$ Ön çapraz bağın hasarı durumunda girişim olmaksızın iyileşmesinin mümkün olmadığının görülmesi ${ }^{[5-7]}$ ve primer tamir uygulanan olgularda istenen sonuçların elde edilememesi $^{[8,9]}$ sonucunda rekonstrüksiyon cerrahisi öne çıkmıştır. Eş zamanlı olarak primer tamir tekniğinde çeşitli yenilikler yapılagelmiştir. Yapılan bu yenilikler ile primer tamirin ÖÇB cerrahisinde olgu seçimine dayalı bir yeri olmasını sağlamak amaçlanmıştır. ${ }^{[10]}$

Karşılaştırmalı yayınlarda günün teknikleri kullanılarak rekonstrüksiyon lehine çalışmaların daha da ağırlık kazanması ile ${ }^{[11]}$ rekonstrüksiyon cerrahisi genel pratikte altın standart cerrahi uygulama haline gelse de primer tamir için çözüm arayışları sonlanmamıştır. Yeni tekniklerin ortaya konulması ve teknik olarak üstünlük sağlayan implantların üretimi, primer tamire yönelik

- İletişim adresi: Prof. Dr. Mahir Mahiroğulları, Vehbi Koç Vakfı Sağlık Kuruluşları Medamerikan Tıp Merkezi, İstanbul Tel: 0532 - 7791379 e-posta: mahirogullari@gmail.com

- Geliş tarihi: 30 Nisan $2020 \quad$ Kabul tarihi: 28 Mayıs 2020 


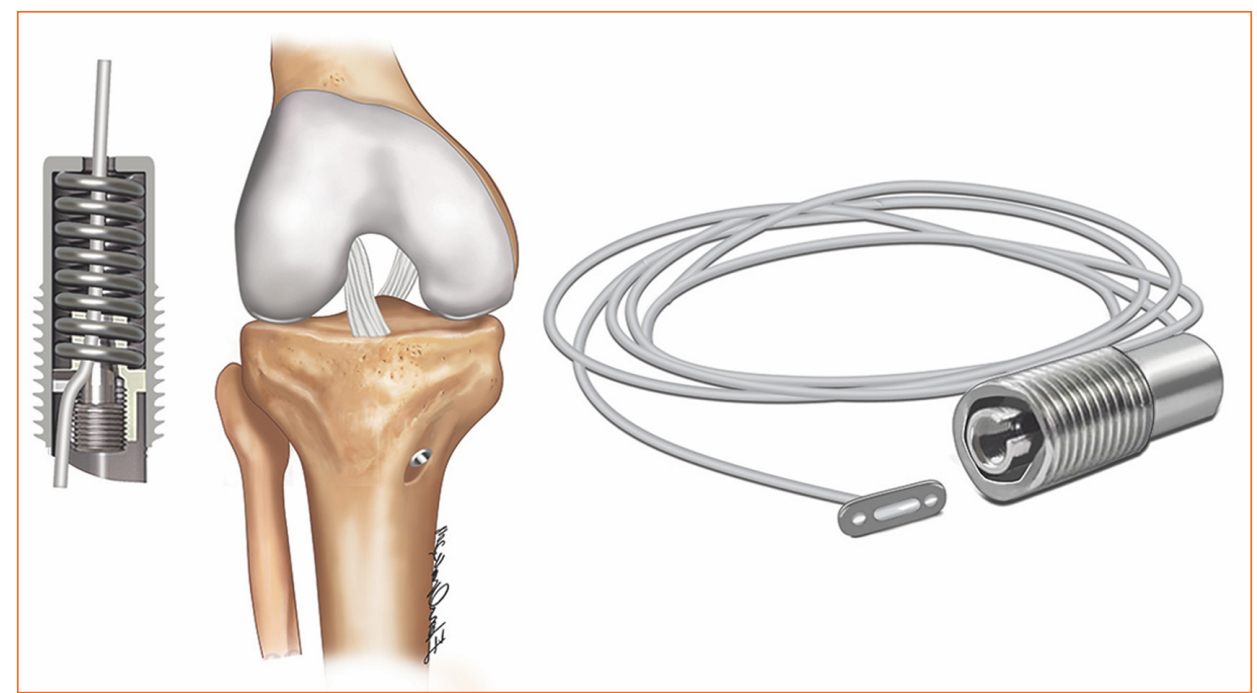

Şekil 1. Dinamik intraligamenter stabilizasyon tekniğinin komponentleri.

eğilime destek sağlamıştır. Bu eğilimin arkasındaki motivasyon unsurları: 1) greft donör saha morbiditesini azaltmak, 2) rekonstrüksiyon ile kaybedilen propriyosepsiyonu muhafaza etmek ve 3) uzun dönemde bazı çalışmalarda, sonuçları tartışmalı olsa da, rekonstrüksiyondan sonra osteoartrit sıklığının azaltılamamış olduğunun görülmesi olarak sayılabilir. ${ }^{[12,13]}$

İlerleyen zaman ile primer tamirin seçilmiş hasta gruplarında uygulanması gerektiğine yönelik görüşler netleşmeye başlamıştır. Buna göre, her ne kadar ÖÇB yırtığının kendi halinde onarımının önünde biyolojik ve mekanik engeller saptanmışsa $\mathrm{da}^{[5-7]}$; proksimal bölge yırtıklarında ${ }^{[4,14,15]}$, erken dönemde ${ }^{[3]}$, kaliteli bakiye (kalan) ÖÇB dokusu varlığında ${ }^{[10]}$ primer tamir ile iyileşme sağlanabileceği iddia edilmiştir.

Modern zamanlarda, farklı yazarlar, tanımladıkları özgün yöntemlerle seçilmiş hasta gruplarında başarılı sonuçlar bildirmiştir. ${ }^{[10,16-18]}$ Buna göre günümüzde yeniden popülerlik kazanan primer tamirde uygulanan üç güncel teknik mevcut olduğu söylenebilir. Bunlardan ilkinde farklı yöntemlerle bağın primer tamiri tariflenmiştir. Sütür ankorlar kullanılarak veya interosseöz tüneller açılarak proksimal bölgedeki ÖÇB yırtığının dikilerek femur tarafına fikse edilebileceği bildirilmiştir. íkinci yöntem, bu tamire ek olarak internal breysleme görevi görecek yapılar kullanılmasıdır. Bu amaçla fiber tape ve benzeri internal sütür destekleri[17,19,20] veya dinamik intraligamenter stabilizasyon (DiS) yöntemi ${ }^{[16]}$ önerilmiştir. Bu yapılar sayesinde dikilerek tamir edilen bağın erken dönemde zorlanmasının önüne geçmek için yapısal destek sağlanması amaçlanmıştır. Üçünncü yöntem olan köprüleme yöntemi ile ÖÇB tamirinde ise (bridge-enhanced anterior cruciate ligament repair-BEAR) ÖÇB'nin eklem içi uzunluğunun \%50 hizasının proksimalinde kalan yırtıklarında, femoral yapışma noktası ile hasar bölgesi boşluğunu köprüleyen biyoaktif bir skafold kullanılarak tamir önerilmiştir. ${ }^{[21]}$

Ön çapraz bağın artroskopik cerrahi tamirinde özel alet ve malzemelerin kullanılması gerekmektedir. Tekniğe göre tibiada bir tünel açılarak veya güdük dokusuna özel aletlerle sütür geçirilmesi ile tamire başlanabilmektedir. $[10,19]$ Tibia tarafinda, sadece tamir uygulanan durumlarda bir tespit gerekmezken; tamir edilen bağın desteklenmesi için bir yapı oluşturulması durumunda tibial tarafa ankor ile tespit uygulanabilmektedir. ${ }^{[19]}$ Takibinde yine tekniğe göre femur tarafinda ankor veya buton kullanılarak tespit yapılabilmektedir. ${ }^{[17,19]}$ Bu bölümde ayrıntıları ele alınacak olan yöntem ise Dis yöntemidir.

\section{DINAMIK INTRALIGAMENTER STABILIZASYON}

Dis yöntemi, tamir ve internal breysleme metotlarının kombinasyonunu içermektedir. Bu sistem üç ana komponentten oluşur. Bunlar: 1) bağın içerisinden geçirilen örgülü polietilen ip, 2) bu ipi ve distal parçadan geçirilmiş sütür materyalini gererek femur tarafında sabitleyen bir düğme ankor ve 3 ) polietilen ipi gererek tamir edilen ÖÇB üzerine düşen yükü azaltan, bir yay ihtiva eden tibial komponenttir (Şekil 1).

\section{Primer Tamirde Neden DiS Yöntemi?}

Dinamik intraligamenter stabilizasyon yönteminin diğer anılan yöntemlere göre tercih edilmesinde etken bazı faktörler sayılabilir. Güncel ÖÇB tamir metodları 
arasında, yukarıda ilk olarak anılan yöntem olan, internal breysleme eklenmeksizin yapılan primer tamir metodunun, ÖÇB iyileşmesi için gerekli olan stabiliteyi sağlayamadığı görülmüş ve internal breysleme ile tamirin desteklenmesi önerilmiştir. ${ }^{[22,23]}$

İnternal breysleme ile tamir edilmiş bağı desteklemek için tibia ve femur tünellerinden geçerek tamir hattını köprüleyen, gerilmiş bir ip kullanılması önerilmiştir. ${ }^{[17]}$ Ne var ki, ÖÇB'nin eklem içi segmentinin, diz sagittal düzlem hareketleri esnasında önemli miktarda esneme gösterdiği bilinmektedir. Bu esneme miktarının özellikle de anatomik femoral tünel açıldığı durumlarda daha da fazla olduğu, ortalamada $6,7 \mathrm{~mm}( \pm 0,9 \mathrm{~mm})$ 'ye ulaştı̆̆ı, biyomekanik kadavra testlerinde ortaya konulmuştur. ${ }^{[24]}$ Fiber tape gibi materyaller ile internal breyslemesi yapılan tamirlerin, diz hareketleri esnasında oluşacak döngüsel kuvvetlere ne ölçüde direnebildiğinin sınandığı biyomekanik bir çalışmada, bu yapıların, Dis sisteminin aksine, döngüsel kuvvetler altında anterior tibial translasyonu kontrol edemeyeceği gösterilmiştir. ${ }^{[22]}$ Başka bir çalışmada ise, ÖÇB'ye iskelet görevi görmesi için kullanılacak ipin, tüneller açılırken izometrik noktalardan sapmalar olduğunda, döngüsel kuvvetlerin olumsuz etkisine karşı savunmasız olacağı bildirilmiştir. ${ }^{[25]}$

DiS tekniğinde ise, internal breysleme için kullanılan polietilen ip, diz $30^{\circ}$ fleksiyonda iken gerilerek kilitlenmekte, böylece tibia anterior translasyonu azaltılarak, tibia femura göre posteriora doğru çekilmiş pozisyonda tespit edilmektedir. Yani tibial anterior translasyon kontrol altına alınmaktadır. ${ }^{[26]}$ Bu durum, tamir edilmiş bağın iyileşmesi için gerekli zemini oluşturur. Ayrıca yay mekanizması, diz tam ekstansiyonda iken, 80 Newton (N) gerginlik altında sistem kilitlenmekte, böylece diz fleksiyona alınırken oluşan esneme, yay sistemi üzerinden olmaktadır. ${ }^{[27]}$ Bu sayede döngüsel kuvvetlere karşı yeterli direnç de sağlanabilmektedir. ${ }^{[22,28]}$ Dis sisteminin harekete izin veren bu yapısal desteği, dinamik augmentasyon (destekleme) modeli olarak isimlendirilmiştir. ${ }^{[22]}$

Dis sistemi kullanıldığında, destekleme yapılmamış primer tamir veya fiber tape ile desteklenmiş primer tamir metotlarına göre, anterior tibial translasyonun (ATT), döngüsel yüklerden sonra bile korunabildiği görülmüştür. Diğer iki yöntem kullanıldığında ise, özellikle döngüsel kuvvetlerin uygulanmasını takiben, bakiye (kalan) ATT anlamlı ölçüde yüksek saptanmıştır. ${ }^{[22]}$ Bu anlamda, Dis sistemi kullanılmasının primer tamir edilmiş bağın iyileşmesi için uygun ortamı sağlayacağı öngörüsü, biyomekanik olarak doğrulanmıştır. Bu sayede, ameliyat sonrası diz eklem hareket açıklığı kısıtlaması gerekmeden, ÖÇB iyileşmesinin sağlanabildiği iddia edilmiştir. ${ }^{[29]}$ Klinik çalışmaların sonuçlarına bağlı gerekçeler, ilerki bölümlerde ayrıntılandırılacaktır.

\section{Tamir Komplikasyonlarına Karşı Özgün Bir Çözüm: Tibial Yay Mekanizması}

Dis yönteminin özgün unsuru tibial taraftaki yay sistemidir. Bu yay sistemi, tamir edilen ÖÇB'nin mekanik periyodik yükten korunmasını sağlar. Sistemin temel olarak iki fonksiyonu öne çıkar: 1) tibiayı, anterior tibial translasyonu kontrol altına alan, örgülü bir polietilen ip kullanarak tespit etmek ve böylece tamir edilmiş güdük uçlarının bir arada kalmasını sağlayarak iyileşme için gerekli zemini oluşturmak ve 2 ) greftin eklem içi segmentinin (bölümünün), diz sagittal eksen hareketleri esnasında göstereceği esnemeyi de göz önüne alarak; bunu tolere edecek esnek bir yapısal özellik sağlamak. Buna göre geliştiriciler, özellikle de anatomik femoral tünel açıldığında, eklem içi greft bölümünde gerçekleşen esneme miktarlarını rehber edinerek ${ }^{[24]}$ ve intra-artiküler giriş noktalarının izometrik olmama ihtimalini de göz önüne aldıklarını iddia ederek, yay mekanizmasını $8 \mathrm{~mm}$ esnemeye izin verecek şekilde tasarlamışlardır. ${ }^{[30]}$

Dis cerrahisinin sonuna doğru, polietilen ip $30^{\circ}$ 'de, anterior tibial translasyonun en fazla ölçülebildiği diz fleksiyon açısında, bu işlem için özel hazırlanmış alet yardımı ile gerilir. Bu sayede yukarıda anılan ilk amaç gerçekleştirilmiş olur. Takibinde yay, diz tam ekstansiyonda iken $80 \mathrm{~N}$ ile gerilir. ${ }^{[31]}$ Geliştiricilerin bildirdiğine göre bu kurvet ile yayda 4 mm'lik bir kısalma sağlanmaktadır. ${ }^{[27]}$ Böylece diz fleksiyona alınırken yay sistemindeki gerginlik azalarak destekleyici ip korunacak, takibinde ise yay esneyerek uzayacak ve tamir bölgesi korunmuş olacaktır. Yukarıda da anıldığı gibi, geliştiriciler, bu amaçla yay sisteminin $8 \mathrm{~mm}$ 'lik bir toplam esneme kapasitesi olduğunu ifade etmiştir. ${ }^{[30]}$

Yayın gerilme kurveti ile ilgili olarak geliştiriciler, 60 $\mathrm{N}$ ile $80 \mathrm{~N}$ arasında bir kuvvet uygulanmasını gerekçe koymaksızın önermişken ${ }^{[32]}$, takip eden bazı yazarlar hastanın 'yapısına' ${ }^{[33]}$ veya cinsiyetine ${ }^{[34]}$ göre 60 $\mathrm{N}$ veya $80 \mathrm{~N}$ ile yayın gerdirilmesini önermiştir. Ancak yapılan daha güncel bir biyomekanik kadavra çalışmasında, DiS sisteminin $60 \mathrm{~N}$ ile değil, ancak $80 \mathrm{~N}$ ile gerdirilmesi durumunda anterior tibial translasyonun tüm diz fleksiyon açılarında kontrol altında tutulabileceği gösterilmiştir. [31]

\section{Cerrahi Teknik}

Hastalar uyluk turnikesi ile cerrahi olarak hazırlanır. Anterolateral ve anteromedial portaller açılır. Diagnostik artroskopiyi takiben proksimal ÖÇB yırtığı teyit edildiği durumda, tibial güdükten PDS dikişler geçirilir. Minimum iki ve maksimum beş tane 2.0 PDS dikiş geçirilmesi tamamlanır. Bu aşamada dikkat edilmesi gereken bir başka nokta da ilk geçirilen dikişin tercihen anterior güdük liflerinden geçirilmesidir. Böylece daha posteriora dikiş atılmak istendiğinde ön 

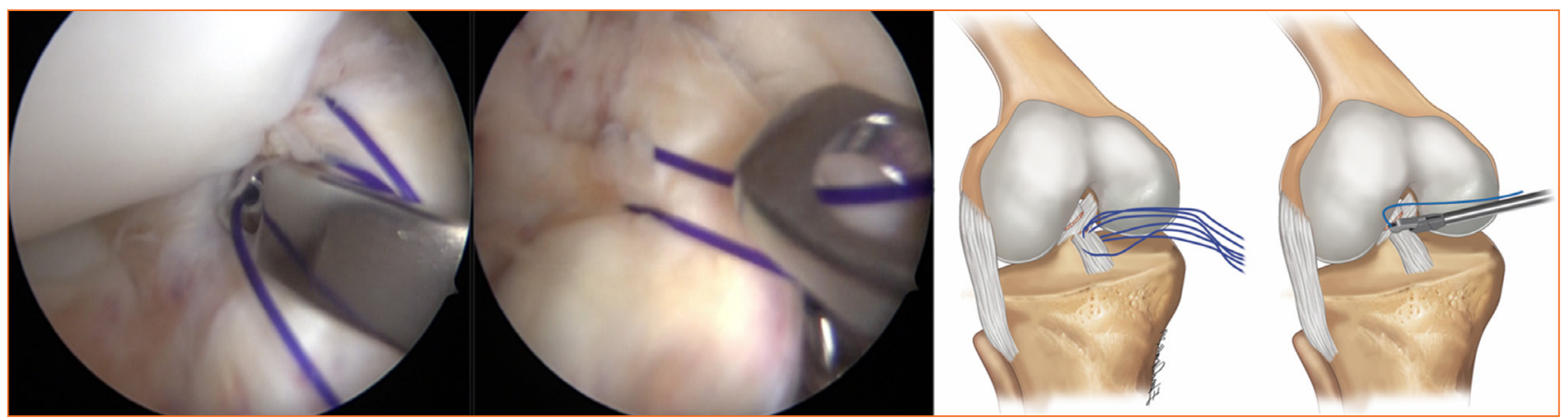

Şekil 2. ÖÇB tibial güdüğü içinden geçirilen PDS dikişler anteromedial portalden dışarı alınır.
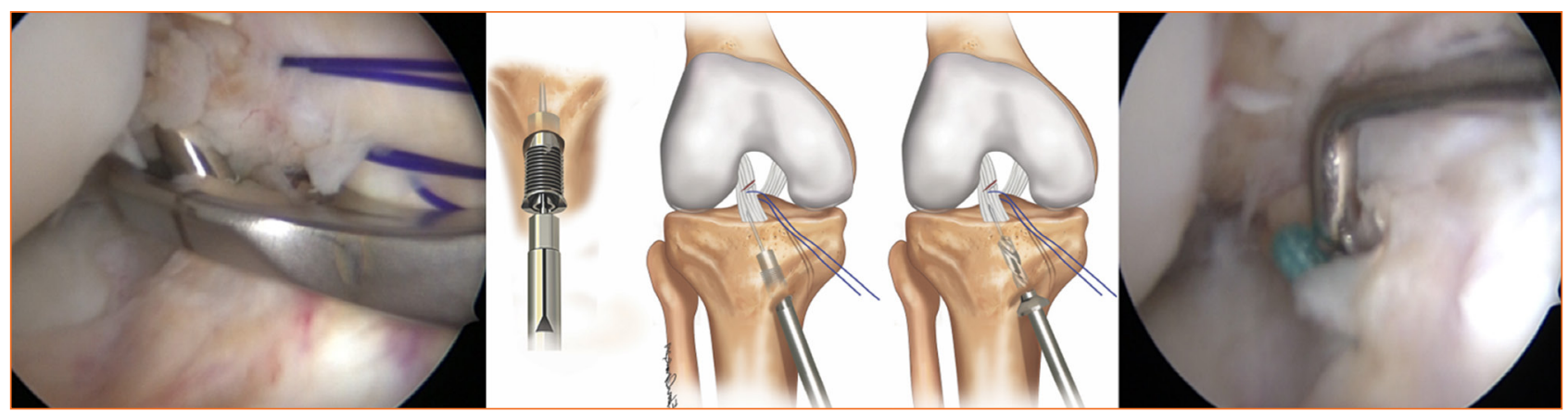

Şekil 3. Tibial rehber telin ÖÇB tibial ayak izine gönderilmesinden sonra tibial implantın yerleştirilmesi ve implant içinden gönderilen taşıyıı ipin anteromedial portalden alınması.

ÖÇB lifleri bu dikiş sayesinde manipüle edilerek posterior kısımlara daha rahat ulaşılabilir. Dikiş geçirme işlemi tamamlanınca geçirilen dikişler anteromedial portalden dışarı çıkarılır (Şekil 2).

Bir sonraki aşamada 3-4 cm'lik bir cilt insizyonu proksimal tibianın medialinde yapılarak tibial implant konulacak bölgeye ulaşılır. Bu bölge pes anserinusun hemen üstüdür. $60^{\circ}$ ye ayarlanmış tibia rehberi ile anteromedial portalden girilerek ÖÇB tibial ayak izinin posterior sınırı saptanır ve tibia içerisinden ince bir tel $(2,3 \mathrm{~mm})$ bu noktaya gönderilir. Tibia içerisinde kat edilen mesafe belirlenir. Rekonstrüksiyon gerekmesi durumu göz önüne alınarak bu mesafenin en az $5 \mathrm{~cm}$ olması amaçlanır. Bu mesafenin ölçülmesi tibial taraftan yapılacak oyma işlemi sırasında intra-artiküler alana düşüp güdüğe ve ayak izine zarar vermenin de önüne geçmeyi sağlar. Takibinde rehber tel üzerinden tibia korteksi delinir ve 10 mm'lik oyucu ile $30 \mathrm{~mm}$ derinliğe kadar oyulur. Bu aşamada rehber telin ileri kaymamasına dikkat etmek popliteal damar ve sinir yapılarını korumak açısından önemlidir. Açılan oyuğa tibial implant yerleştirilir ve tibial rehber teli uzaklaştırılır. Tibial implant içerisinden girilerek eklem içerisine taşıyıcı ip yerleştirilir. Bu ip de anteromedial portalden dışarı taşınır (Şekil 3).
Takibinde diz $120^{\circ}$ fleksiyonda iken ÖÇB'nin femoral ayak izi üzerinden girilerek femoral rehber yerleştirilir. Rehber tel lateral femur distali yüzeyinden çıkarılır. Bu bölgede küçük bir insizyon yapılır. Yumuşak doku genişleticisi tel üzerinden femur korteksine kadar kaydırılarak rehber tel çevresi genişletilir. ÖÇB tibial güdüğünden geçirilmiş PDS ipler ve taşıyıcı ip, rehber telin alt ucunda bulunan taşıma deliğinden geçirilir ve rehber telin proksimalden çekilmesi ile femoral tünelin üst ucuna taşınmış olur (Şekil 4).

Taşıyıcı ipe polietilen ip yüklenir ve ucuna flip ankor yerleştirilmiş polietilen ip, tibial implant üzerinden retrograd çekilir (Şekil 5). Bu aşamada flip ankora bir kurtarıcı ip yerleştirmek, gereken durumlarda ankoru geri çekmek ve yumuşak dokudan ankorun dik şekilde geçmesini sağlamak için etkilidir. Yumuşak dokudan dik şekilde geçirilen flip ankor femurun lateral korteksi üzerine yatay şekilde yerleştirilir. Bu noktada bağın karşılıklı uçlarının bir araya gelmesi için tibial güdükten geçirilmiş olan iplerin proksimal taraftan, polietilen ipin ise distalden gerdirilmesi uygun bir yaklaşım olacaktır.

Takibinde femoral çentik bölgesinde mikrokırık işlemi uygulanır. Polietilen ipin distale çekilmesi ve 


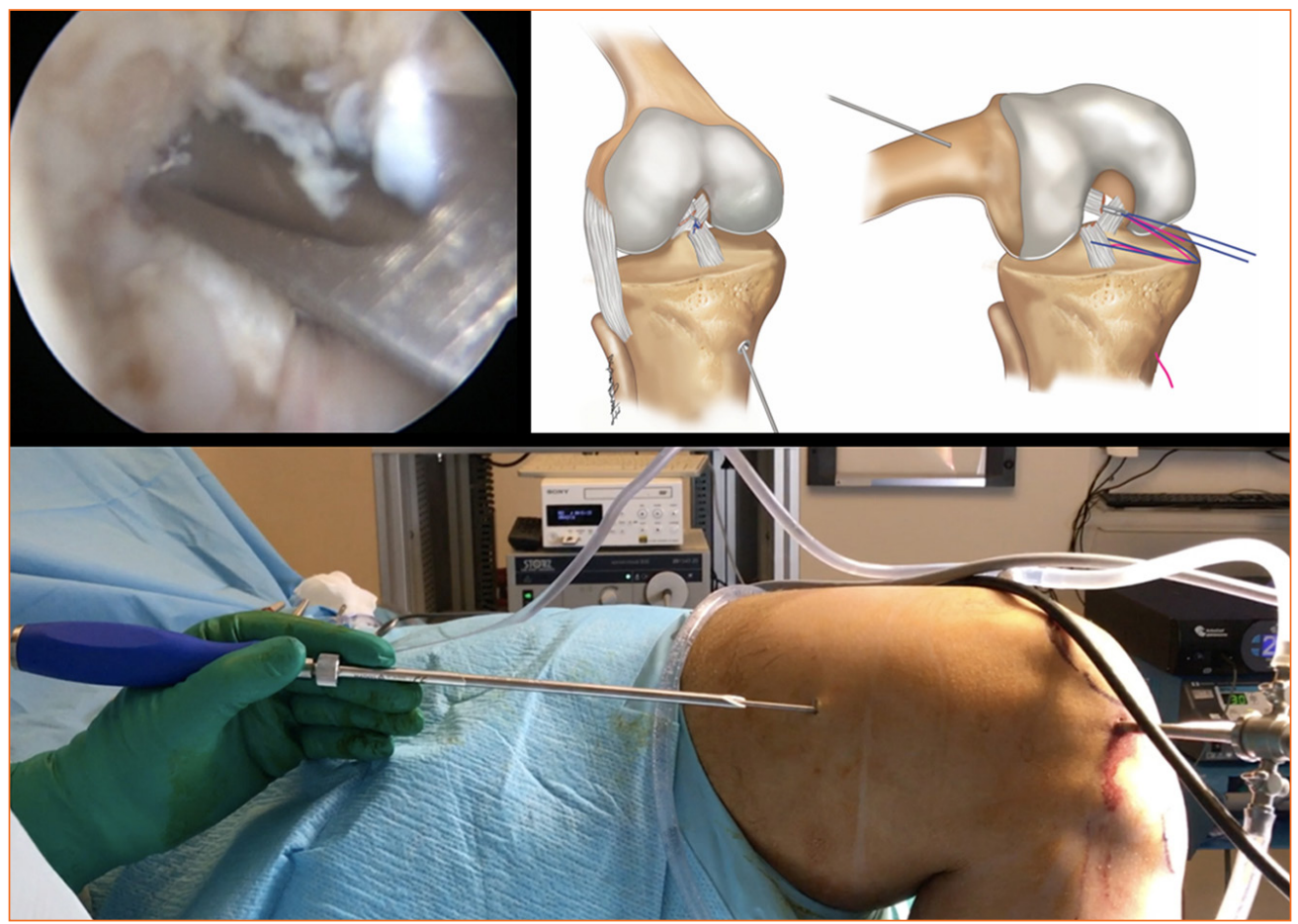

Şekil 4. ÖÇB'nin femoral ayak izi üzerinden gönderilen rehbere tele PDS ve taşıyıcı ipin yerleştirilerek femur lateral yüzeyindeki mini insizyondan dışarı çıkarılması.

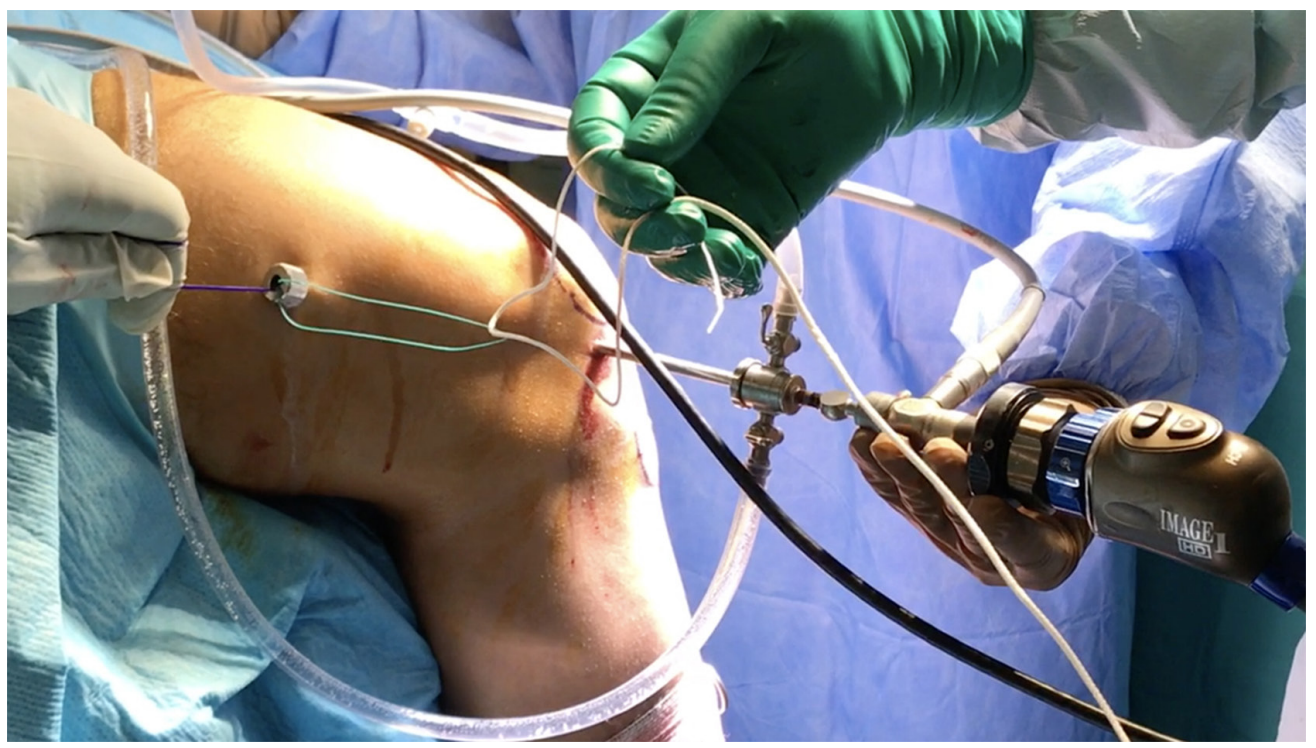

Şekil 5. Lateralden iplerin taşınması. Beyaz renkli kalın bant eklem içerisinde kalacak destekleyici banttır.

gerdirilmesi aşamasına geçilir. Gerdiriciyi, tibial implant üzerine doğru bir şekilde yerleştirmek önemlidir. Yerleştirme işlemi tamamlanınca diz $30^{\circ}$ fleksiyona getirilir. Takibinde mandallı sistem, gerdirici skalası görünmeyecek hale gelene kadar çevrilir. İpi gerdirmek için özel olarak tasarlanmış tornavida $(3,5 \mathrm{Nm})$ yerine yerleştirilerek germe işlemine başlanır. Özel tornavida saat yönünde çevrilerek femur tarafındaki flip ankorun kortekse oturması ve örgülü polietilen ipin gerilmesi sağlanmış olur. Üç klik sesi duyulduğunda işlem tamamlanır. Bu esnada PDS iplerin proksimalden gergin tutulmaya devam edilmesi gerekmektedir. 


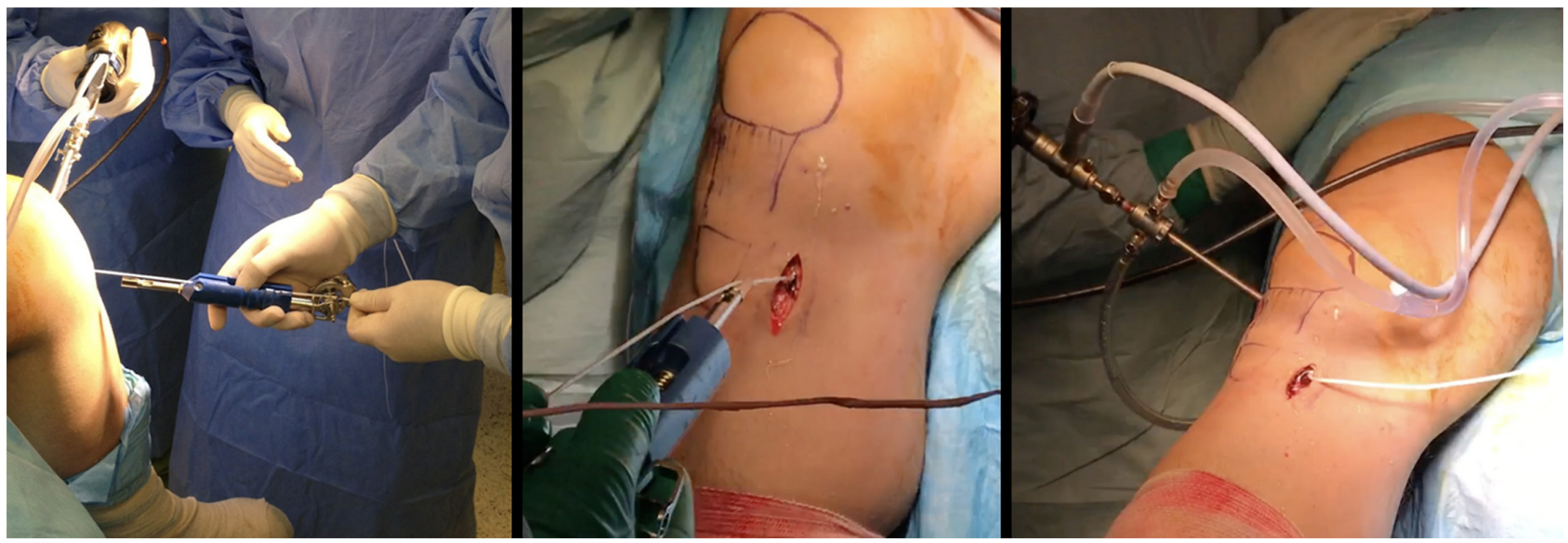

Şekil 6. Gerdirici tornavidanın yerleştirilmesi, ayarlanması ve gerdirme işlemi bittikten sonraki görüntü.

Takibinde sistem tamamen gevşetilir ve diz tam ekstansiyona getirilir. İp gerici tornavida uzaklaştırılır ve özel torklu, yay gerici tornavida, gerdirici aparatın üzerinde bu amaçla yapılmış yerine yerleştirilir. Özel aparatı sayesinde 80 N'lik (8 kg) kuvvet ile yay gerdirilir. Bu gerdirme, kolun saat yönü tersine çevrilmesi ile sağlanır. Takibinde ise sistemi kilitleyecek olan koni, tornavida ile yerine oturtulur. Tibial güdük içerisinden geçirilen ve femoral taraftan çıkarılan iplerin ek bir tespitine ihtiyaç yoktur. Bu iplerle birlikte flip ankordaki kurtarıcı ip kesilip çekilir. Polietilen ipin tibial implantı aşan fazlalık kısmı da kesilerek uzaklaştırılır (Şekil 6).

Cerrahi teknik proksimal yırtıklar için yukarıdaki gibi tariflenmişken, orta bölgedeki (mid-substance) ÖÇB yırtıklarında ayrıca proksimal güdük dokusundan da PDS ip geçirilerek, tibia tarafında açılan ikinci bir tünele tespit yapıldığı da bildirmiştir. ${ }^{[27]}$

Başka bir grup ise, güdüğün parçalandığı veya orta bölgedeki yırtıklarda, daha etkin olarak güdüğe hakim olabilmek için omuz artroskopisindeki gibi kement düğüm atmayı sağlayan ekipman kullandıklarını bildirmiştir. Yazarlar, bu şekilde femoral tünele üç kement düğümünün sığabileceğini bildirmiştir. ${ }^{[34]}$

\section{Hasta Seçimi}

Primer tamir yapılacağı durumlarda, erken müdahale gerektiği konusunda 1950 yılına dayanan yayınlardan ${ }^{[3]}$ modern derlemelere ${ }^{[23]}$ kadar öneriler bulmak mümkündür. DiS söz konusu olduğunda da öneriler, yaralanmanın takibindeki 14 ila 21 günde cerrahinin yapılmış olması konusunda birleşmektedir. ${ }^{16,33,34]}$
DiS sistemini geliştiren ekip, ilk hasta gruplarına ait yayınlarda, ÖÇB yırtıklarında lokasyon farkı gözetilmeden DiS'in uygulanabileceğini bildirmiştir. Ekibin hasta seçimi kriterleri: 1) <45 yaş, 2) 14 günden az süre geçmiş olan yeni yırtık, 3) düzenli spor aktivitesi yapmak, 4) primer tamir yapılacak dizden daha önce cerrahi geçirmemiş olmak şeklindedir. ${ }^{[16]}$ Ancak takip eden dönemdeki klinik çalışmalarla, endikasyonları daraltan bazı sonuçlara varılmıştır. Buna göre orta bölgedeki yırtıklar ve yaralanma öncesi yüksek spor aktivite düzeyi (Tegner >7), başarısız sonuçlarla ilişkili bulunmuştur. ${ }^{[35]}$ Dis kullanılmış hastaların beş yıllık takiplerinde sağkalım analizi yapan Ahmad ve ark. da, benzer şekilde, yaralanma öncesi yüksek aktiviteyi (Tegner >7) sağkalım üzerinde olumsuz bir faktör olarak saptamışlardır. Ancak yazarların bu çalışmalarında, orta ve distal kesim ÖÇB yırtığı tamirlerini kohortlarından çıkararak analiz yaptıkları gözlenmiştir. ${ }^{[36]}$

Başka bir çalışmada ise, DiS sonrası revizyon cerrahisi gerekmiş hasta grubu incelenmiştir. Bu çalışmada, düşük yaş, yaralanma öncesi yüksek spor aktivite düzeyi (Tegner $>5$ ) ve takiplerde yüksek diz laksisitesi revizyon cerrahisi riskini artıran faktörler olarak saptanmıştır. Ancak yırtığın lokasyonu ve şekli ile revizyon riski arasında anlamlı fark bulunmamıştır. ${ }^{[37]}$

Henle ve ark. ${ }^{[29]}$ tarafindan daha önce önerilmiş olan ÖÇB yırtığı sınıflamasına göre yırtığın lokasyonu, tipi ve sinovyal kılıfın hasarına göre üçer dereceli bir tanımlama yapılmıştır. Buna göre sınıflamanın ilk hanesinde proksimal bölge yırtıkları A, orta kısım $B$, distal kısım C ile tanımlanmıştır. İkinci hanede yırtığın tipi belirtilmiştir: "1" ile yırtık güdüğünün tek parça olduğu, "2" ile iki demet halinde olduğu, " 3 " ile multipl demetler halinde olduğu ifade edilmiştir. 


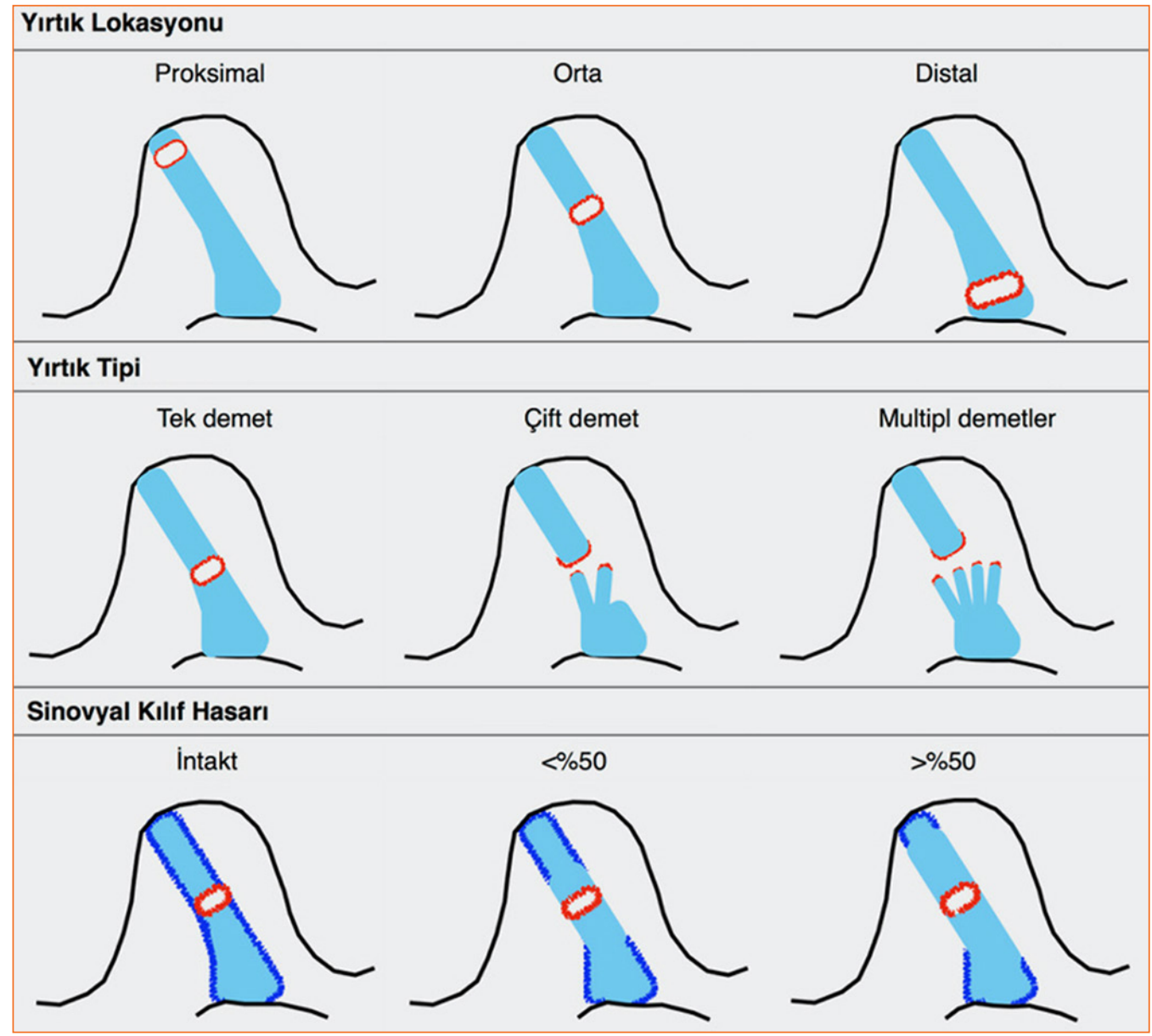

Şekil 7. Ön çapraz bağ yırtıkları sınıflaması.

Üçüncü hanede ise sinovyal kılıfın tasviri yapılmıştır: "1" ile tamamen sağlam kılıf, "2" ile \%50'den fazla sağlam kılıf, "3" ile de \%50'den az sağlam kılıf varlığı ifade edilmiştir (Şekil 7). Sınıflamayı önerdikleri çalışmada 278 hastanın takip sonuçlarını paylaşan yazarlar, en sık lokalizasyonunun proksimal $(\% 73,4)$, en nadir lokalizasyonunun ise distal kesim $(\% 0,4)$ olduğunu; en sık yırtık tipinin tek demet $(\% 46,8)$, en nadir olarak ise multipl demetler şeklinde olduğu $(\% 16,5)$; sinovyal kılıfın ise $\% 24,8$ hastada sağlam, $\% 50,4$ hastada ise \%50'den fazla sağlam olduğunu bildirmiştir. ${ }^{[29]}$

Hasta seçim kriterleri, farklı merkezlerden cerrahların bildirdiği ve daha güncel yayınlarda daralmaya devam etmiştir. Proksimal yırtıklar cerrahi için önerilen lokasyonu teşkil etmeye başlamıştır. ${ }^{[36,38]}$ Ancak lokasyonun yanında, yırtık şeklinin ve sinovyanın sağlamlık durumunun da sonuçlarda etkili olabileceği bildirilmiştir. ${ }^{[38]}$
Farklı bazı yazarların DiS endikasyonları aşağıdaki gibidir:

Ateschrang ve ark. ${ }^{[39]}$ :

- Yaş $>18$

- Akut rüptür

- Kapalı fizler

- Anteroposterior translasyonun yan yana testte $>5$ mm olması

- Ligamentin proksimal 1/3'ündeki yırtıklar

- Tegner $>4$ olan, aktif hastalar

Ahmad ve ark. ${ }^{[36]}$ :

- Yaş >18

- Yaralanma gününden itibaren 21 günü geçmemiş

- Anteroposterior translasyon $25^{\circ}$ diz fleksiyonunda, KT-1000 ile $134 \mathrm{~N}$ uygulanırken, $>5 \mathrm{~mm}$ olması 
- IKDC sınıflaması C veya D olması (International Knee Documentation Committee)

- Tegner >4 olan aktif hastalar

- Proksimal ÖçB yırtığı olması

Kosters ve ark. randomizasyon ile, primer tamir veya ÖÇB rekonstrüksiyonu yaptıkları çalışmalarında, proksimal yırtığı primer tamir için zorunlu endikasyon kabul etmediklerini, dört hastalarında orta kesimde ÖÇB yırtığı olduğunu, ancak bunların tamamının PDS dikişler geçirildikten sonra redükte edilebildiği için tamire devam edildiğini bildirmiştir. ${ }^{[40]}$

Hoogeslang ve ark. tarafindan randomizasyon ile yapılan benzer bir çalışmada da yırtık lokasyonunun çaIışmaya alım kriteri olarak kullanılmadığı, yaralanmanın üzerinden 21 günden az süre geçmiş, Tegner skoru 5 ile 10 arasında olan kişilerin çalışmaya dâhil edildiği bildirilmiştir. ${ }^{[41]}$

Dis uygulaması için fizlerin kapanmış olması [32,39], yaşın $>18$ olması ve yaralanmanın üzerinden 21 günden fazla geçmemiş olması ${ }^{[16,39,41]}$ genel kabul görmüş endikasyonlardır. Yaş için bir üst sınır bildirilmemiş olmakla birlikte, geliştiriciler, erken dönem fizibilite çaış̧malarında 45 yaş altı hastalara Dis uyguladıklarını bildirmiştir. ${ }^{[16]}$ Geliştiricilerin takip eden çalışmalarında 63 yaşına kadar hasta opere ettikleri de anlaşılmaktadır. ${ }^{[29]}$ Karşılaştırmalı bir çalışmada, $18-55$ yaş arası hastalar çalışmaya dâhil edilmişken ${ }^{[42]}$, bir başka ülkeden bildirilen yayında ise $18-60$ yaş arası hastaların tercih edildiği bildirilmiştir. ${ }^{[34]}$

Özetlenecek olursa, güncel yayınlarda kabul görmüş, Dis metodu için kısıtlı endikasyonlar aşağıdaki gibi sayılabilir:

- Proksimal bölgede konumlu yırtıklar ${ }^{[35,36,38]}$

- Orta bölgede konumlu, ancak dikişe uygun doku içeren, sinovyanın korunduğu ve güdük uçları redükte edilebilen yırtıklar[ ${ }^{40]}$

- Fizleri kapanmış hastalar ${ }^{[32,39]}$

- Yaralanmanın üzerinden 21 günden fazla geçmemiş hastalar ${ }^{[16,39,41]}$

- Pivot aktivitesi ve spor aktivitesi profesyonel nitelikte ve seviyede olmayan; eğlence veya egzersiz amaçlı (rekreasyonel) spor yapan kişiler (Tegner $4-8)^{[35,38,40]}$

- Yaş $>18^{[30,34,36,38,42]}$

\section{Klinik Sonuçlar}

Hayvan deneylerinde başarılı sonuçlar verdiği görülen DiS sistemi ${ }^{[43]}$, önce pilot bir hasta grubunda ${ }^{[16]}$, daha sonra ise geniş hasta gruplarında uygulanmıştır. ${ }^{[29]}$ Yukarıdaki bölümlerde ayrıntıları paylaşılan bazı çalışmalarda; öncelikle sistemi geliş̧tiren Bern grubu tarafından bildirilen cerrahi sonuçları ${ }^{[29,30,37]}$; farklı ülkelerden de bazı başarılı sonuçlar takip etmiştir. ${ }^{[39-41]}$ Buna karşılık, bazı yazarlar ise Dis yöntemi ile artmış komplikasyonlar ve olumsuz sonuçlar bildirmiştir. ${ }^{[44,45]}$ Bu bölümde güncel olan çalışmalar ile komplikasyon oranı yüksek olan çalışmalar ele alınacaktır.

Bağımsız bir grup tarafından yapılmış olma, randomize kontrollü dizaynıla önem kazanan güncel bir çaIışma, Hoogeslag ve ark. tarafından yayımlanmıştır. ${ }^{41]}$ Yazarlar, iki yıl takipli hastalarının sonuçlarını paylaşmıştır. Dis ile tamir edilen grubun \%16,7'si proksimal bölge yırtığı olmamasına rağmen; DiS yöntemi kullanıldığında, ÖÇB rekonstrüksiyonuna (ÖÇBR) göre, subjektif hasta skorlarında (IKDC) fark görülmediği bildirilmiştir. Ancak, Dis kullanıldığında re-rüptür hariç nedenlerle ikinci cerrahi gerekliliği ÖÇBR'ye göre daha fazla olmuştur (\%20,8'e karşı \%14,3). Bunun nedeninin, siklops lezyonuna bağlı oluşan şişlik veya ekstansiyon defisiti olabileceği düşünülmüsştür. Yazarlar, ÖÇB dokusunun iyileşebilmek için ürettiği yara dokusuna bağlı olarak bu durumun görülmüş olabileceğini değerlendirmiştir. Yazarlar ayrıca, ameliyat öncesi yüksek aktivitenin, Dis uygulanan olgularda re-rüptür olasılı̆̆ını artırdığının gösterilmiş olmasına rağmen, ne DiS ne de ÖÇBR grubunda saptanan re-rüptür değerlerinin literatüre göre fark gösterdiğini saptayabilmiştir. ${ }^{[1]}$ Bu anlamda yüksek ameliyat öncesi aktivitenin, Dis için olduğu kadar ÖÇBR için de risk teşkil ettiği bilinerek, bu konuda daha yüksek hasta sayısıyla, iyi dizayn edilmiş çalışmalara ihtiyaç duyulduğu anlaşılmaktadır.

Bağımsız, bir başka güncel randomize kontrollü çalışmada, fonksiyonel sonuçlarda DiS ve ÖÇBR arasında fark saptanamadığı bildirilmiştir. Kosters ve ark., rolimetre ile anterior tibial translasyonu (ATT) belirledikleri çalışmada, DiS ile tamir sonucunda ÖÇBR'ye göre daha yüksek ATT değerleri saptanmış olsa da, klinik olarak yetersizlik oranlarının, her iki grup arasında benzer olduğunu göstermiştir. Ancak artmış objektif laksisiteye rağmen, subjektif instabilite yokluğundan dolayı revizyon gerekmemiştir. ${ }^{[40]}$

Meister ve ark., kısa dönem (12 ay) takip sonuçlarını bildirdikleri çalışmalarında, DiS'in \%15 re-rüptür riski olduğunu ve re-rüptür ve artrofibrozis ile birlikte \%35'e varan ikinci operasyon gerekliliğini bildirmişlerdir. Ancak yazarların, çalışmaya dahil edilme kriterlerinde, yırtık sınıflamasını önemsemedikleri anlaşılmaktadır. Bildirilene göre, bu konuda yapılmış randomize kontrollü çalışmalarda karşılaşılan yırtık sınıflamalarından bile çok farklı olarak ${ }^{[40,41]}$, bu çalışma kohortunun yüksek oranda orta ve distal bölgede (\%38), multipl 


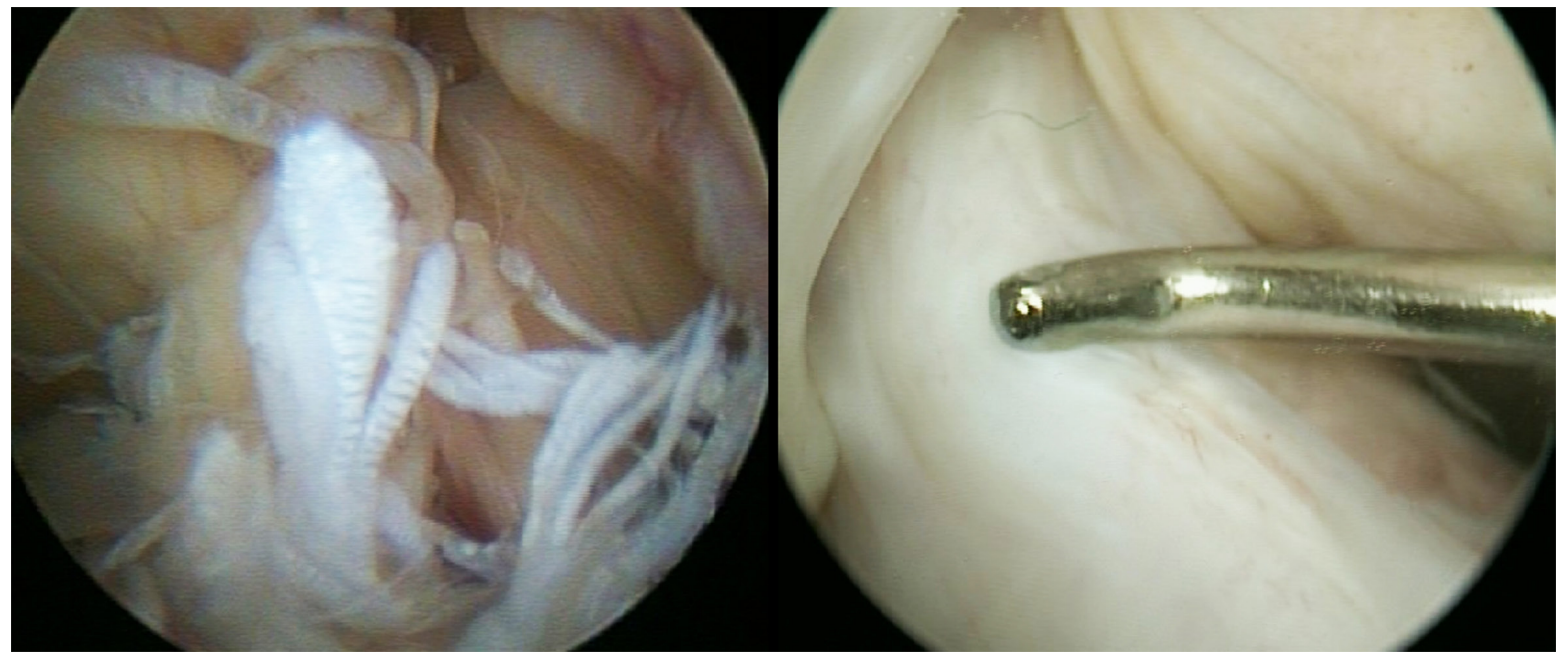

Şekil 8. Soldaki resimde akut ÖÇB yırtığı olup primer tamir ettiğimiz hastanın 8. aydaki ikincil bakı artroskopisindeki iyileşmiş hali sağdaki resimde görülmektedir.

demet içeren (\%31) ve \%50'den fazla sinovyal hasarIı tipte (\%31) yırtık içerdiği anlaşılmaktadır. ${ }^{[4]}$ Bu tür olgu özelliklerinin endikasyonlardan çıkarılmış olduğu göz önüne alındığında bildirilen sonuçların önemi azalmaktadır.

Osti ve ark., 57 hastayı takip ettikleri çalışmalarında 30 hastada $(\% 52,6)$ yeniden cerrahi gerektiğini, toplam 33 hastada $(\% 57,9)$ komplikasyon görüldüğünü bildirmişlerdir. Komplikasyonlar olarak, re-rüptür veya iyileşmeme $(\% 17,5)$, menisküs yırtığına $(\% 15,4)$, siklops sendromuna $(\% 30,8)$, hareket kısıtlılığına $(\% 53,8)$, artrofibrozise $(\% 5,3)$ veya implant irritasyonuna bağı $(\% 12,3)$ tekrar artroskopi gerekliliği sayılmıştır. Hasta kohortunun 15 ile 54 yaşları arasında olduğu bildirilmiştir. Yazarlar, daha önce bildirilmiş tüm çalışmalardan farklı olarak; menisküs tamiri yaptıkları hastaların bir kısmında (\%54), rehabilitasyonda farklı bir süreç takip etmiş ve bu grubu da çalışma kohortunda bırakmıştır. Bu hastaların altı hafta, sadece 10 kg yük vererek mobilize olduğu ve diz breysi kullandığı; bunun ilk üç haftasında fleksiyonun $60^{\circ}$ ye kısıtlandığı bildirilmiştir. Ayrıca bu çalışmada da ÖÇB rüptür lokalizasyonu tamir için bir kontrendikasyon teşkil etmemiş ve hastaların \%16'sında orta ve distal yırtıklar tamir edilmiştir. ${ }^{[45]}$

DiS mekanizmasının en önemli özelliklerinden birinin primer tamir yapısını koruyan yay sistemi olduğu unutulmamalıdır. Bu yapının varlığı, iyileşme için döngüsel kuvvetlere dayanıklı bir zemin hazırlamanın yanında, erken rehabilitasyona, diz fleksiyonunda hiç bir kısıtlama olmadan izin verdiği için anlamlıdır.
Öte yandan, her ne kadar ÖÇBR hastalarında yapılmış bir çalışma olsa da, geniş hasta serili güncel bir çalışmada, siklops sendromu için en önemli risk faktörünün kalan ÖÇB dokusu değil, ameliyat sonrası erken dönemde ekstansiyonun kazanılamaması olduğunu bildirilmiştir. ${ }^{[46]}$

Osti ve ark.'nın ${ }^{[45]}$ bildirdiği veriler göz önüne alınarak, Dis uygulanması planlanan hastalarda, rehabilitasyon değişikliğine yol açabilecek ek patolojilere yönelik girişim düşünüldüğünde, ÖÇBR seçeneği göz önüne alınabilir.

Son olarak, iyileşen doku özelliği ile ilgili bir çalışma yapmış olan Ateschrang ve ark.'nın bildirdiğine göre, iyileşme dokusu normal ÖÇB'nin \%50'si veya \%75'i seviyesinde kalan, ATT mesafeleri ikincil bakı artroskopisi esnasında 6,7 ya da $8 \mathrm{~mm}$ ölçülen hastalarda bile subjektif fonksiyonel sonuçlar (ortalama Lysholm: 100 ) ve ameliyat sonrası spor aktivitesi skorları (ortalama Tegner: 7) mükemmel olabilmektedir. ${ }^{[39]}$ Bu durum, DiS ile erken spora dönüş sağlanmasına ve propriyosepsiyonun korunmasına bağlı olabilir. Ancak, bu konuda kanıta dayalı çıkarımlar için, bu ve benzeri verilerin çoğalması gerekmektedir.

Kendi yaptığımız 15 hastalık olgu serimizde hastalarımızın kısa ve orta dönem sonuçlarını takip etme fırsatımız olmuştur. Bu seride özellikle femoral taraf yırtıklarında oldukça başarılı bir yöntem olarak değerlendirilmiştir. Bir hastamızda tamir ameliyatından sekiz ay sonra, vida çıkarma ameliyatı esnasında yapılan ikincil bakı artroskopisinde yırtı ÖÇB'nin tamamen iyileştiği görülmektedir (Şekil 8). 


\section{Ameliyat Sonrası Rehabilitasyon}

Ameliyat sonrası hastaların dizi üç ila beş gün boyunca ekstansiyonda bloklanır. Üç günden sonra üç haftaya kadar tolere edilen ölçüde yük vermeye başlanır. Bu aşamada diz fleksiyonunda herhangi bir kısıtlama uygulanmaz. Dördüncü haftadan itibaren tam yük verilebilir ve kapalı zincir diz egzersizleri ile kuadriseps ve hamstring adaleleri güçlendirilir. Denge egzersizleri ile propriyosepsiyon çalışmaları yapılabilir. Ameliyat sonrası altıncı haftadan sonra koşuya başlanabilir ve üçüncü aydan sonra dizin rotasyonel zorlanmalarına neden olan pivot sporlar yapılabilir. Rekabet içeren sporlar ve kayma için beş aydan sonrası uygun görülmektedir.

\section{SONUÇ}

Güncel bilimsel çalışmalar ile, Dis yönteminin klinikte uygulanması biyomekanik hayvan ve kadavra testleri ile desteklenmiştir. ${ }^{[28,31,43]}$ Karşılaştırmalı testler ile DiS sisteminin diğer primer tamir destekleyici yöntemlerden daha avantajlı olduğu da gösterilmiştir. ${ }^{[22]} \mathrm{Bu}$ veriler ışığında gerçekleştirilen, bağımsız, randomize kontrollü çalışmaların da Dis ile primer tamiri destekleyen sonuçları ortaya çıkmıştır. ${ }^{[40,41]}$ Yöntemi kullandıklarında olumsuz sonuçlarla karşılaştıklarını bildiren bağımsız çalışmaların, hasta seçme ve rehabilitasyonu konularında, çeşitli metodolojik hatalar içerdikleri gözlenmiştir. ${ }^{[4,45]}$

Bu veriler ışı̆̆ında, bilimsel kanıt zemininde, DiS sisteminin seçilmiş hasta gruplarında önemli bir yeri olduğu anlaşıımaktadır. Varolan kullanım alanının değişmesinde, gelecek dönemde yapılacak bağımsız, geniş serili, karşılaştırmalı ve randomize çalışmaların etkisi olacaktır.

\section{KAYNAKLAR}

1. Mall NA, Chalmers PN, Moric M, Tanaka MJ, Cole BJ, Bach BR, Paletta GA. Incidence and trends of anterior cruciate ligament reconstruction in the United States. Am J Sports Med 2014;42(10):2363-70. Crossref

2. Paschos NK, Howell SM. Anterior cruciate ligament reconstruction: principles of treatment. EFORT Open Rev 2016;1(11):398-408. Crossref

3. O'Donoghue $\mathrm{DH}$. An analysis of end results of surgical treatment of major injuries to the ligaments of the knee. J Bone Joint Surg Am 1955;37-A(1):1-13. Crossref

4. Marshall JL, Warren RF, Wickiewicz TL. Primary surgical treatment of anterior cruciate ligament lesions. Am J Sports Med 1982;10(2):103-7. Crossref

5. Trager D, Pohle K, Tschirner W. Anterior cruciate ligament suture in comparison with plasty. A 5-year follow-up study. Arch Orthop Trauma Surg 1995;114(5):278-80. Crossref

6. Fleming BC, Carey JL, Spindler KP, Murray MM. Can suture repair of $A C L$ transection restore normal anteroposterior laxity of the knee? An ex vivo study. J Orthop Res 2008;26(11):1500-5. Crossref
7. Ahn JH, Chang MJ, Lee YS, Koh KH, Park YS, Eun SS. Nonoperative treatment of ACL rupture with mild instability. Arch Orthop Trauma Surg 2010;130(8):1001-6. Crossref

8. Feagin JA Jr, Curl WW. Isolated tear of the anterior cruciate ligament: 5-year follow-up study. Am J Sports Med 1976;4(3):95-100. Crossref

9. Odensten M, Lysholm J, Gillquist J. Suture of fresh ruptures of the anterior cruciate ligament. A 5-year follow-up. Acta Orthop Scand 1984;55(3):270-2. Crossref

10. Difelice GS, van der List JP. Arthroscopic Primary Repair of Proximal Anterior Cruciate Ligament Tears. Arthrosc Tech 2016;5(5):e1057-61. Crossref

11. Drogset JO, Grøntvedt T, Robak OR, Mølster A, Viset AT, Engebretsen L. A sixteen-year follow-up of three operative techniques for the treatment of acute ruptures of the anterior cruciate ligament. J Bone Joint Surg Am 2006;88(5):944-52. Crossref

12. Strand $T$, Mølster A, Hordvik M, Krukhaug Y. Long-term follow-up after primary repair of the anterior cruciate ligament: clinical and radiological evaluation 15-23 years postoperatively. Arch Orthop Trauma Surg 2005;125(4):21721. Crossref

13. Murray MM, Fleming BC. Use of a bioactive scaffold to stimulate anterior cruciate ligament healing also minimizes posttraumatic osteoarthritis after surgery. Am J Sports Med 2013;41(8):1762-70. Crossref

14. Strand T, Engesaeter LB, Mølster AO, Raugstad TS, Stangeland L, Stray O, Alho A. Knee function following suture of fresh tear of the anterior cruciate ligament. Acta Orthop Scand 1984;55(2):181-4. Crossref

15. Weaver JK, Derkash RS, Freeman JR, Kirk RE, Oden RR, Matyas J. Primary knee ligament repair --revisited. Clin Orthop Relat Res 1985;(199):185-91. Crossref

16. Eggli S, Kohlhof $H$, Zumstein $M$, Henle $P$, Hartel M, Evangelopoulos DS, Bonel H, Kohl S. Dynamic intraligamentary stabilization: novel technique for preserving the ruptured ACL. Knee Surg Sports Traumatol ArthrosC 2015;23(4):1215-21. Crossref

17. van der List JP, DiFelice GS. Arthroscopic Primary Anterior Cruciate Ligament Repair with Suture Augmentation. Arthrosc Tech 2017;6(5):e1529-34. Crossref

18. Murray MM, Kalish LA, Fleming BC, Flutie B, Freiberger C, Henderson RN, Perrone GS, Thurber LG, Proffen BL, Ecklund K, Kramer DE, Yen YM, Micheli LJ; BEAR Trial Team. BridgeEnhanced Anterior Cruciate Ligament Repair: Two-Year Results of a First-in-Human Study. Orthop J Sports Med 2019;7(3):2325967118824356. Crossref

19. Heusdens CHW, Hopper GP, Dossche L, Mackay GM. Anterior Cruciate Ligament Repair Using Independent Suture Tape Reinforcement. Arthrosc Tech 2018;7(7):e747-53. Crossref

20. Jonkergouw A, van der List JP, DiFelice GS. Arthroscopic primary repair of proximal anterior cruciate ligament tears: outcomes of the first 56 consecutive patients and the role of additional internal bracing. Knee Surg Sports Traumatol Arthrosc 2019;27(1):21-8. Crossref

21. Murray MM, Flutie BM, Kalish LA, Ecklund $K$, Fleming BC, Proffen BL, Micheli LJ. The Bridge-Enhanced Anterior Cruciate Ligament Repair (BEAR) Procedure: An Early Feasibility Cohort Study. Orthop J Sports Med 2016;4(11):2325967116672176. Crossref

22. Hoogeslag RAG, Brouwer RW, Huis in 't Veld R, Stephen JM, Amis AA. Dynamic augmentation restores anterior tibial translation in ACL suture repair: a biomechanical comparison of non-, static and dynamic augmentation techniques. Knee Surg Sports Traumatol Arthrosc 2018;26(10):2986-96. Crossref 
23. van Eck CF, Limpisvasti O, ElAttrache NS. Is There a Role for Internal Bracing and Repair of the Anterior Cruciate Ligament? A Systematic Literature Review. Am J Sports Med 2018;46(9):2291-8. Crossref

24. Lubowitz $\mathrm{JH}$. Anatomic $\mathrm{ACL}$ reconstruction produces greater graft length change during knee range-of-motion than transtibial technique. Knee Surg Sports Traumatol Arthrosc 2014;22(5):1190-5. Crossref

25. Hoogeslag RAG, Brouwer RW, Huis in 't Veld R, Amis AA. Isometric placement of the augmentation braid is not attained reliably in contemporary $A C L$ suture repair. Knee 2020;27(1):111-23. Crossref

26. Kohl S, Evangelopoulos DS, Ahmad SS, Kohlhof $\mathrm{H}$, Herrmann G, Bonel H, Eggli S. A novel technique, dynamic intraligamentary stabilization creates optimal conditions for primary ACL healing: a preliminary biomechanical study. Knee 2014;21(2):477-80. Crossref

27. Kohl S, Evangelopoulos DS, Schär MO, Bieri K, Müller T, Ahmad SS. Dynamic intraligamentary stabilisation: initial experience with treatment of acute ACL ruptures. Bone Joint J 2016;98-B(6):793-8. Crossref

28. Haberli J, Henle P, Acklin YP, Zderic I, Gueorguiev B. Knee joint kinematics with dynamic augmentation of primary anterior cruciate ligament repair --a biomechanical study. J Exp Orthop 2016;3(1):29. Crossref

29. Henle P, Röder C, Perler G, Heitkemper S, Eggli S. Dynamic Intraligamentary Stabilization (DIS) for treatment of acute anterior cruciate ligament ruptures: case series experience of the first three years. BMC Musculoskelet Disord 2015;16:27. Crossref

30. Eggli S, Röder C, Perler G, Henle P. Five year results of the first ten $A C L$ patients treated with dynamic intraligamentary stabilisation. BMC Musculoskelet Disord 2016;17(1):105. Crossref

31. Schliemann B, Lenschow S, Domnick C, Herbort M, Haeberli J, Schulze M, Wähnert D, Raschke MJ, Kösters C. Knee joint kinematics after dynamic intraligamentary stabilization: cadaveric study on a novel anterior cruciate ligament repair technique. Knee Surg Sports Traumatol Arthrosc 2017;25(4):1184-90. Crossref

32. Haeberli J, Jaberg L, Bieri K, Eggli S, Henle P. Reinterventions after dynamic intraligamentary stabilization in primary anterior cruciate ligament repair. Knee 2018;25(2):271-8. Crossref

33. Kösters C, Herbort M, Schliemann B, Raschke MJ, Lenschow S. Dynamic intraligamentary stabilization of the anterior cruciate ligament. Operative technique and short-term clinical results. Unfallchirurg 2015;118(4):364-71. Crossref

34. Heusdens $\mathrm{CH}$, Dossche L, Zazulia K, Michielsen J, Van Dyck P. Tips and Tricks to Optimize Surgical Outcomes After ACL Repair Using Dynamic Intraligamentary Stabilization. Surg Technol Int 2019;36. http://surgicaltechnology.com/ OpenAccess/1214-Heusdens-OS-FINAL-cr.pdf

35. Krismer AM, Gousopoulos L, Kohl S, Ateschrang A, Kohlhof H, Ahmad SS. Factors influencing the success of anterior cruciate ligament repair with dynamic intraligamentary stabilisation. Knee Surg Sports Traumatol Arthrosc 2017;25(12):3923-8. Crossref
36. Ahmad SS, Schürholz K, Liechti EF, Hirschmann MT, Kohl S, Klenke FM. Seventy percent long-term survival of the repaired $A C L$ after dynamic intraligamentary stabilization. Knee Surg Sports Traumatol Arthrosc 2020;28(2):594-8. Crossref

37. Henle P, Bieri KS, Brand M, Aghayev E, Bettfuehr J, Haeberli J, Kess M, Eggli S. Patient and surgical characteristics that affect revision risk in dynamic intraligamentary stabilization of the anterior cruciate ligament. Knee Surg Sports Traumatol Arthrosc 2018;26(4):1182-9. Crossref Correction: Crossref

38. Ateschrang A, Schreiner AJ, Ahmad SS, Schröter S, Hirschmann MT, Körner D, Kohl S, Stöckle U, Ahrend MD. Improved results of ACL primary repair in one-part tears with intact synovial coverage. Knee Surg Sports Traumatol Arthrosc 2019;27(1):37-43. Crossref

39. Ateschrang A, Ahmad SS, Stöckle U, Schroeter S, Schenk $W$, Ahrend MD. Recovery of ACL function after dynamic intraligamentary stabilization is resultant to restoration of $\mathrm{ACL}$ integrity and scar tissue formation. Knee Surg Sports Traumatol Arthrosc 2018;26(2):589-95. Crossref

40. Kösters C, Glasbrenner J, Spickermann L, Kittl C, Domnick C, Herbort M, Raschke MJ, Schliemann B. Repair with Dynamic Intraligamentary Stabilization Versus Primary Reconstruction of Acute Anterior Cruciate Ligament Tears: 2-Year Results from a Prospective Randomized Study. Am J Sports Med 2020;48(5):1108-16. Crossref

41. Hoogeslag RAG, Brouwer RW, Boer BC, de Vries AJ, Huis in 't Veld R. Acute Anterior Cruciate Ligament Rupture: Repair or Reconstruction? Two-Year Results of a Randomized Controlled Clinical Trial. Am J Sports Med 2019;47(3):56777. Crossref

42. Bieri KS, Scholz SM, Kohl S, Aghayev E, Staub LP. Dynamic intraligamentary stabilization versus conventional $A C L$ reconstruction: A matched study on return to work. Injury 2017;48(6):1243-8. Crossref

43. Kohl S, Evangelopoulos DS, Kohlhof $\mathrm{H}$, Hartel M, Bonel $\mathrm{H}$, Henle P, von Rechenberg B, Eggli S. Anterior crucial ligament rupture: self-healing through dynamic intraligamentary stabilization technique. Knee Surg Sports Traumatol Arthrosc 2013;21(3):599-605. Crossref

44. Meister M, Koch J, Amsler F, Arnold MP, Hirschmann MT. $A C L$ suturing using dynamic intraligamentary stabilisation showing good clinical outcome but a high reoperation rate: a retrospective independent study. Knee Surg Sports Traumatol Arthrosc 2018;26(2):655-9. Crossref

45. Osti M, El Attal R, Doskar W, Höck P, Smekal V. High complication rate following dynamic intraligamentary stabilization for primary repair of the anterior cruciate ligament. Knee Surg Sports Traumatol Arthrosc 2019;27(1):29-36. Crossref

46. Delaloye JR, Murar J, Vieira TD, Franck F, Pioger C, Helfer L, Saithna A, Sonnery-Cottet B. Knee Extension Deficit in the Early Postoperative Period Predisposes to Cyclops Syndrome After Anterior Cruciate Ligament Reconstruction: A Risk Factor Analysis in 3633 Patients from the SANTI Study Group Database. Am J Sports Med 2020;48(3):565-72. Crossref 